\title{
The neuropathic itch: Do not scratch your head too hard!
}

Soumya Patnaik ${ }^{1}$, John $\operatorname{Imms}^{1}$, and Gabor Varadi ${ }^{2}$

${ }^{1}$ Affiliation not available

${ }^{2}$ Albert Einstein Medical Center

October 16, 2020

\begin{abstract}
Although less common compared to postherpetic neuralgia, post herpes itch (PHI) is a known sequela after herpetic infections. PHI usually disappears over weeks to months, requiring only symptomatic management. Rarely, PHI can result in significant debilitation. We report one case of extreme post herpetic itching and review the available literature.
\end{abstract}

\section{Hosted file}

post herpetic itching.pdf available at https://authorea.com/users/367681/articles/487153-theneuropathic-itch-do-not-scratch-your-head-too-hard

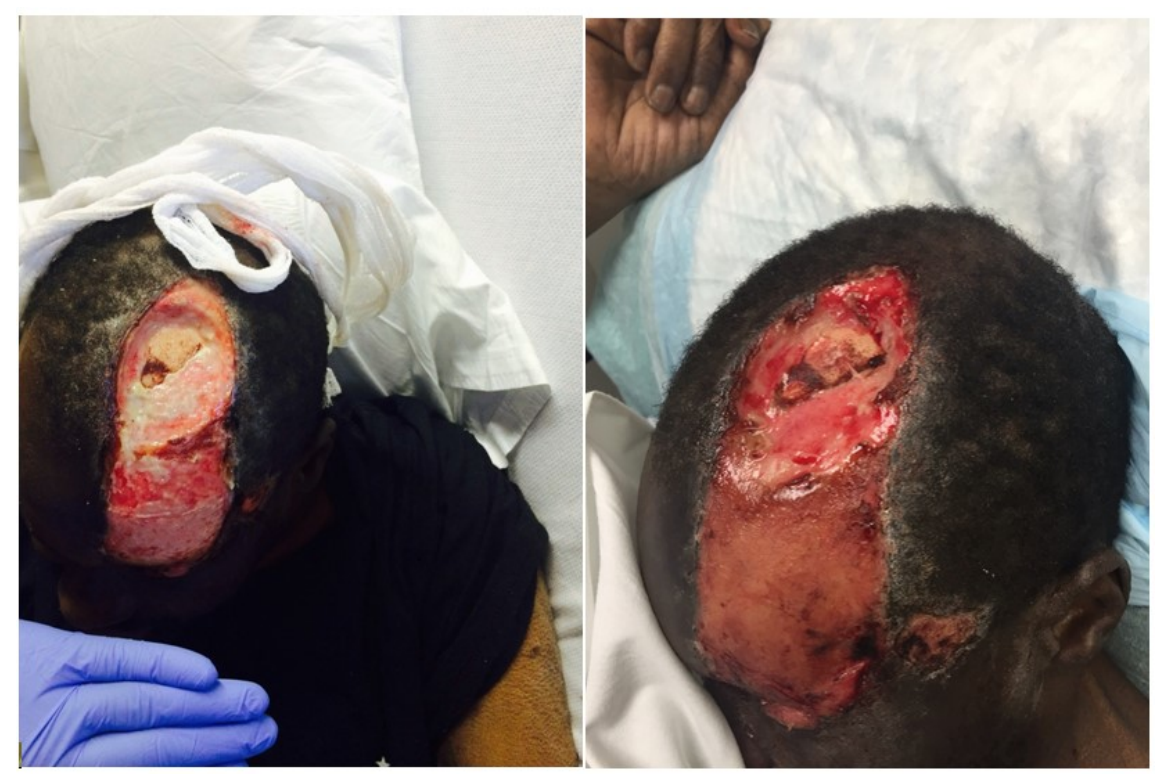




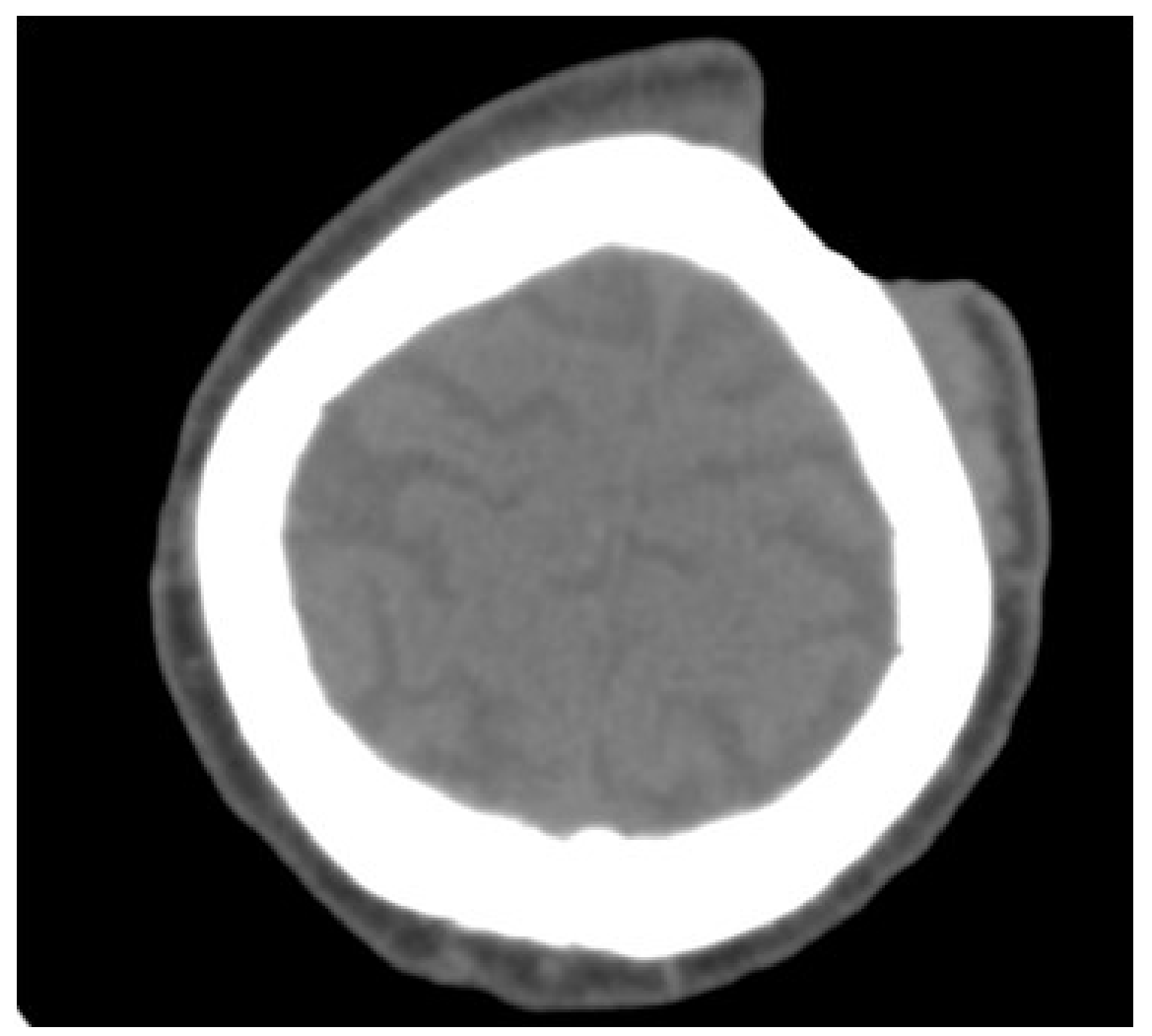

